\title{
Follicular thyroid lesions: is there a discriminatory potential in the computerized nuclear analysis?
}

\author{
Flávia O Valentim', Bárbara P Coelho', Hélio A Miot², Caroline Y Hayashi', Danilo T A Jaune', \\ Cristiano C Oliveira ${ }^{3}$, Mariângela E A Marques ${ }^{3}$, José Vicente Tagliarini ${ }^{4}$, Emanuel C Castilho ${ }^{4}$, \\ Paula Soares ${ }^{5,6,7}$ and Gláucia M F S Mazeto \\ ${ }^{1}$ Internal Medicine Department, Botucatu Medical School, Sao Paulo State University (Unesp), Botucatu, São Paulo, Brazil \\ 2Department of Dermatology, Botucatu Medical School, Sao Paulo State University (Unesp), Botucatu, São Paulo, Brazil \\ ${ }^{3}$ Pathology Department, Botucatu Medical School, Sao Paulo State University (Unesp), Botucatu, São Paulo, Brazil \\ ${ }^{4}$ Otolaryngology and Head and Neck Surgery Department, Botucatu Medical School, Sao Paulo State University (Unesp), Botucatu, São Paulo, Brazil \\ ${ }_{5}$ i3S - Instituto de Investigação e Inovação em Saúde, Universidade do Porto, Porto, Portugal \\ ${ }^{6}$ Cancer Signaling and Metabolism Group, Institute of Molecular Pathology and Immunology of the University of Porto (IPATIMUP), Porto, Portugal \\ ${ }^{7}$ Department of Pathology, Medical Faculty, University of Porto, Porto, Portugal
}

Correspondence should be addressed to G M F S Mazeto: gmazeto@fmb.unesp.br

\begin{abstract}
Background: Computerized image analysis seems to represent a promising diagnostic possibility for thyroid tumors. Our aim was to evaluate the discriminatory diagnostic efficiency of computerized image analysis of cell nuclei from histological materials of follicular tumors.

Methods: We studied paraffin-embedded materials from 42 follicular adenomas

(FA), 47 follicular variants of papillary carcinomas (FVPC) and 20 follicular carcinomas

$(\mathrm{FC})$ by the software ImageJ. Based on the nuclear morphometry and chromatin texture, the samples were classified as FA, FC or FVPC using the Classification and Regression Trees method.

Results: We observed high diagnostic sensitivity and specificity rates (FVPC: $89.4 \%$ and $100 \%$; FC: $95.0 \%$ and $92.1 \%$; FA: 90.5 and $95.5 \%$, respectively). When the tumors were compared by pairs (FC vs FA, FVPC vs FA), $100 \%$ of the cases were classified correctly. Conclusion: The computerized image analysis of nuclear features showed to be a useful diagnostic support tool for the histological differentiation between follicular adenomas, follicular variants of papillary carcinomas and follicular carcinomas.
\end{abstract}

Key Words
- adenocarcinoma
- follicular
- carcinoma
- papillary
- cell nucleus
- histology
- thyroid neoplasms

Endocrine Connections (2018) 7, 907-913

\section{Introduction}

The differential diagnosis of thyroid follicular lesions includes both benign tumors, such as follicular adenoma (FA) and malignant tumors, such as follicular carcinoma (FC) and follicular variant of papillary carcinoma (FVPC). This diagnosis can be difficult, especially considering FA and FC, in which the distinction depends on detecting vascular and/or capsular invasion and demands thorough evaluation of the histological material

http://www.endocrineconnections.org https://doi.org/10.1530/EC-18-0237

(C) 2018 The authors Published by Bioscientifica Ltd
(1). Thus, both incomplete lesion excision, lacking a sample of the infiltrated tumor capsule portion, and the extra time required to assess the entire tumor extension hinder the differential diagnosis between FA and FC (2) and can make it unfeasible.

Changes in nuclear morphometry and chromatin texture are classically described by pathologists as factors that differentiate normal tissues from neoplasms.

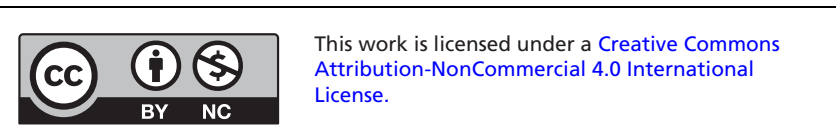


Morphological analysis of cell nuclei by histology may provide data about cellular physiology and contribute to the establishment of the diagnosis and prognosis of neoplastic lesions (3). Computerized image analysis is an objective and highly reproducible tool in daily practice and has proven to be a promising resource for assessing thyroid lesions. More widely used for assessing histological material $(1,4,5,6,7,8,9,10)$, computerized image analysis enables the detection of very subtle nuclear changes (11), whose investigation could also provide data for cytological material analysis $(11,12,13)$.

However, specifically for follicular-patterned tumors, nuclear parameters that can correctly differentiate malignant from benign lesions have not yet been established. This could be partly due to the small number of samples analyzed in previous studies, to absence of normalization of the results by nuclear dimension and to the assessment of few nuclear parameters $(1,11,13)$. Hence, the objective of this study was to evaluate the discriminatory diagnostic efficiency of computerized image analysis of cell nuclei in histological materials obtained from FA, FC and FVPC.

\section{Materials and methods}

Design, patients and histological material processing

This cross-sectional study used computerized image analysis to compare the nuclear morphometry and chromatin texture features of thyroid tumor tissues and healthy thyroid tissue (Fig. 1) and to assess its diagnostic accuracy. When making models using machine learning methods, overfitting should always be considered.
Therefore, the ideal in those cases would be to evaluate a large sample and to divide it into a training group, which develops the evaluation algorithm, and a validation group, which applies the developed algorithm and measures its performance. This is a preliminary study, in which the training was carried out resulting in the development of the algorithm to be validated later.

Stored histological materials of 103 patients with histopathological diagnoses of FA, FC and FVPC were analyzed. The patients had undergone total thyroidectomy between 1993 and 2016 at the Clinics Hospital of Botucatu School of Medicine. The study population was first characterized by gender and age. Next, two experienced pathologists (MEAM and CCO) assessed the thyroid tissue to confirm the diagnoses based on histopathological parameters (14). A total of 109 tumors from 103 patients were included: 42 FA, 47 FVPC and 20 FC (six patients presented two lesions: five had FA and FVPC and one had FA and FC). Tissue adjacent to the benign tumors (FA) was used as representing normal thyroid tissue (NT). Three micron sections were cut from paraffin-embedded representative tissue samples and stained with hematoxylin-eosin (HE).

This study was approved by the Research Ethics Committee of Botucatu School of Medicine - Unesp under protocol number 635,459, issued on May 05, 2014.

\section{Image acquisition}

The slides were scanned and photographed (43× magnification; PANORAMIC MIDI II - 3D Histech, Japan; http://3dhistech.com/pannoramic_midi) and numbered randomly. Two to three photos were captured

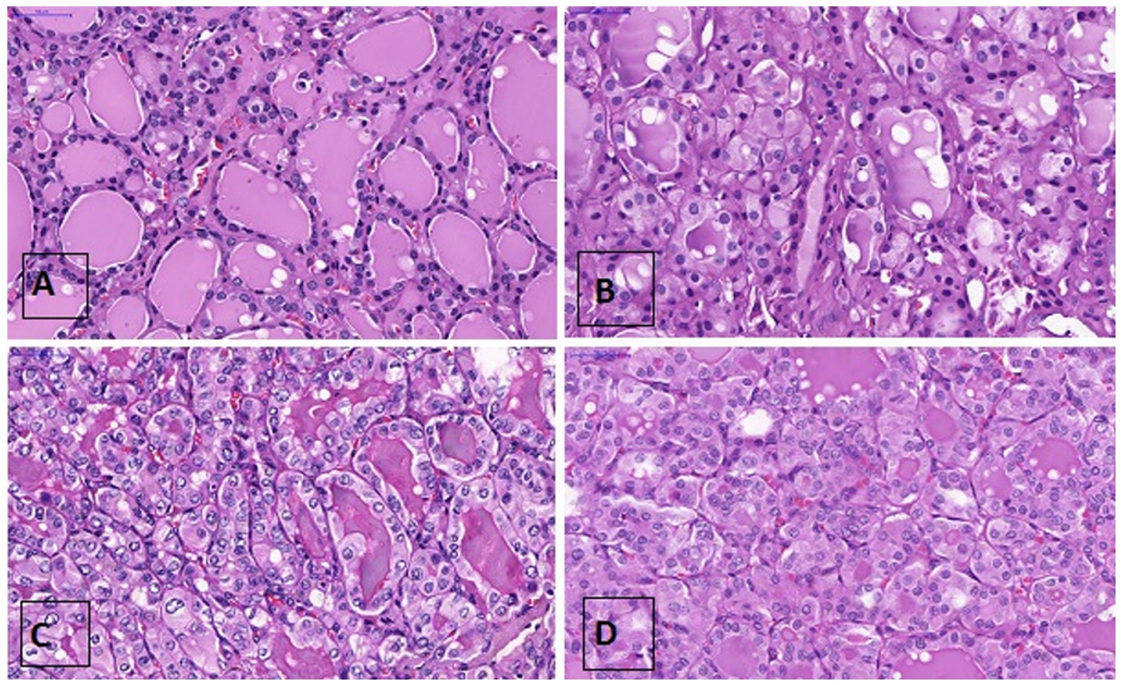

Figure 1

Thyroid tissues analyzed: normal thyroid (A), follicular adenoma (B), follicular variant of papillary carcinoma (C), and follicular carcinoma (D). Hematoxylin-eosin staining, $\times 20$. http://www.endocrineconnections.org https://doi.org/10.1530/EC-18-0237 (c) 2018 The authors Published by Bioscientifica Ltd

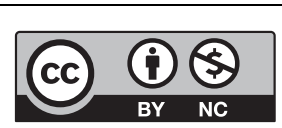

This work is licensed under a Creative Commons Attribution-NonCommercial 4.0 International License. 
from each slide. Thyroid neoplasms may be quite heterogeneous and choosing a slide area to photograph could result in different nuclear representativeness. Therefore, the photographs were captured from the most representative areas presenting a higher number of nuclei, and the best photo of each slide was chosen to be analyzed, based on the judgment of two experienced pathologists (MEAM and CCO).

\section{Image analysis}

The images were analyzed by two researchers who did not know the histopathological diagnosis of the samples (blind analysis). The diameters of the tumors in each slide were measured in centimeters, and the nuclei were analyzed by the free software ImageJ (http://imagej.net/ Downloads). The software turns color images into black and white images containing 256 shades of gray (16 bits), which allows better analysis of chromatin compaction and eliminates color-based differences between the samples (10). The nuclei in the edited photographs were manually selected and analyzed individually. Agglomerated or overlapping nuclei were excluded. A pilot study determined the minimum number of nuclei that should be analyzed in each photograph - anything above that minimum would not affect the results of the statistical analysis. Sixty nuclei per photograph would be sufficient (data not shown) based on a standard error of $5 \%$ for each variable. Thus, a total of 9060 nuclei were assessed, including the NT samples.

For each selected nucleus, the program provides a list of morphometric and texture parameters, allowing the user to select the parameters of interest for nuclear assessment (16). We also calculated secondary indicators (variation coefficients) related to these parameters. Hence, morphometric assessment included: area, perimeters, circularity, larger diameter (Feret), ratio between larger and smaller diameter (Aspect Ratio, AR), index area per Feret, ratio between perimeter and area $(\mathrm{P} / \mathrm{A})$, ratio between area and Feret (area/Feret) and index perimeter/ area. The selected texture features were mean and median gray intensity (expressed in a scale of 256 shades of gray, in which higher numbers mean lighter nuclei: $0=$ black; $255=$ white), standard deviation of gray intensity (STDEV), roughness (RA), regularity of nuclear membrane (Round), solidity, fractal dimension (Fractal), entropy and ratio between gray intensity and area (gray intensity/area). The calculated secondary indicators were coefficient of variation $(\mathrm{CV})$ of area, CV-Mean intensity, CV-STDEV, CV-Perimeter, CV-Circularity, CV-Feret, CV-Median

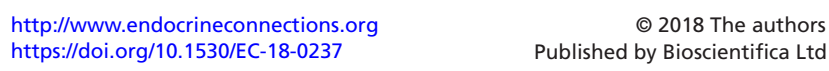

intensity, CV-AR, CV-Round, CV-Solidity, CV-Fractal, CV-Entropy, CV-Perimeter/area and CV-RA. The software expressed these parameters as pixels, which were later transformed into microns.

\section{Comparison and classification of the tumors}

The tumor and the healthy thyroid tissues were initially compared for morphometric and textural aspects of chromatin. Later, tumors with histological diagnoses of FA, FC and FVPC were analyzed for these nuclear parameters with the Classification and Regression Trees (CRT) method, which provided a reclassification for them. The diagnosis provided by the CRT was then compared to the histological diagnosis, thus evaluating the method's ability to correctly classify these lesions. Since the major doubt when facing a follicular pattern tumor resides in differentiating benign from malignant lesions, the tumors were also analyzed by pairs (malign vs benign: FC vs FA, FVPC vs FA).

\section{Statistical analysis}

The frequencies of females by tumor diagnosis were compared by the chi-square test. The patients' ages, greater tumor diameter and nuclear parameters were expressed as medians and quartiles (p25-p75) and compared by the Kruskal-Wallis test. Based on the study nuclear features, the tumors were reclassified by the CRT method and twoing algorithm (impurity measure). This statistical method constructs a tree model, with predictive character of the data, that starts from a root and branches out, from nodes that use cut-offs for the parameters analyzed, provided by the model itself (17). The sensitivity, specificity and area under the receiver operator characteristic (ROC) curve (AUC) were calculated for each tumor to determine the validity of the classification method. The various nuclear morphometric and texture parameters were also correlated with greater tumor diameter using Spearman's rho coefficient. The software IBM SPSS/Windows (version 22) performed all statistical analyses using a significance level of $5 \%$.

\section{Results}

FC patients were older $(P=0.04)$ than FVPC patients and their tumors had larger diameters $(P=0.001)$ than FVPC. The FA did not differ from the other tumors in these parameters. No significant differences were present

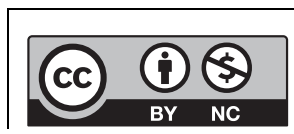

This work is licensed under a Creative Commons Attribution-NonCommercial 4.0 International License. 
Table 1 General data of 109 tumors in 103 patients.

\begin{tabular}{|c|c|c|c|c|}
\hline \multirow[b]{2}{*}{ Parameter } & \multicolumn{3}{|c|}{ Diagnosis of the tumors } & \multirow[b]{2}{*}{$P$} \\
\hline & FA & FVPC & $\mathrm{FC}$ & \\
\hline Patients* $(n)$ & 36 & 47 & 20 & - \\
\hline Women $(n(\%))$ & $34(94.4)$ & $44(93.6)$ & $15(75.0)$ & 0.41 \\
\hline Age $\left(\right.$ years) ${ }^{\dagger}$ & $54(44 ; 60)^{\mathrm{ab}}$ & $52(39 ; 59)^{a}$ & $61(46 ; 73)^{b}$ & 0.04 \\
\hline $\begin{array}{l}\text { Larger } \\
\text { diameter }(\mathrm{cm})^{\dagger}\end{array}$ & $2.5(1.2 ; 3.5)^{a b}$ & $1.5(1 ; 3)^{a}$ & $3.5(3 ; 4.2)^{\mathrm{b}}$ & 0.001 \\
\hline
\end{tabular}

*Only the worst diagnosis was considered. ${ }^{\dagger}$ Median (25th percentile, 75th percentile). Statistical test: Kruskal-Wallis. Different letters mean statistical difference $(b>a ; P<0.05)$.

FA, follicular adenoma; FC, follicular carcinoma; FVPC, follicular variant of papillary carcinoma.

concerning the gender distribution according to diagnosis $(P=0.41)$ (Table 1$)$. Tumor diameter was not associated with the study morphometric and texture parameters (Supplementary Table 1, see section on supplementary data given at the end of this article), except for the CV-STDEV parameters, which were weakly negatively correlated $(r=-0.24 ; P=0.02)$. Therefore, the results were not corrected by tumor diameter.

All the studied primary nuclear parameters differed significantly $(P<0.05) \quad$ (Table 2 and Supplementary Table 2) between the different lesions, but not the secondary indicators (variation coefficients) CV-Area $(P=0.08)$, CV-STDEV $(P=0.24)$, CV-Feret $(P=0.22)$, and CV-AR $(P=0.05)$ (Supplementary Table 2$)$.

When the nuclear parameters of the three tumors were analyzed by the CRT regression model (Fig. 2) based on the CV-RA parameters, the resulting global classification matched the actual diagnoses in $90.8 \%$ of the cases, with sensitivities of $95,90.5$ and $89.4 \%$ for FC, FA and FVPC, respectively (Supplementary Table 3). The specificities and AUC were 92.1-100\% and 0.93-0.95, respectively (Table 3). When only FC and FA were analyzed, correct global classification was achieved for $100 \%$ of the tumors (Fig. 3 and Supplementary Table 4). Likewise, when only FVPC and FA were analyzed, correct global classification was also achieved for $100 \%$ of the cases (Supplementary Fig. 1 and Supplementary Table 5).

\section{Discussion}

Numerous studies have attempted to determine an efficient and accurate diagnostic method for follicularpatterned thyroid nodules (2). One of the techniques that has been used for this purpose is computerized image analysis of cell nuclei $(4,5,7,8,12,18,19,20,21)$, which has proven promising but not entirely conclusive.

This preliminary study uses computerized image analysis of cell nuclei and a classification method, which proved capable of correctly identifying high percentages of FA, FC and FVPC by image analysis obtained from the histological materials. Assessment of these three follicular-patterned tumors enabled us to correctly globally classify more than $90 \%$ of the cases. Additionally, high sensitivities (between $89.4 \%$ and 95\%),

Table 2 Morphometric and textural primary parameters, according to the histological material evaluated.

\begin{tabular}{l} 
Parameter \\
\hline Area $\left(\mu \mathrm{m}^{2}\right)$ \\
Mean gray intensity ${ }^{\dagger}$ \\
STDEV \\
Perimeter $(\mu \mathrm{m})$ \\
Circularity \\
Feret $(\mu \mathrm{m})$ \\
Median gray intensity ${ }^{\dagger}$ \\
AR \\
Round \\
Solidity \\
Fractal \\
Entropy \\
Perimeter/area ( $\mu \mathrm{m})$ \\
RA \\
Area/feret ( $\mu \mathrm{m})$ \\
Gray intensity/area (unidades/ $\mu \mathrm{m}^{2}$ )
\end{tabular}

\begin{tabular}{ccc}
\hline & Histopathologin & FA \\
\cline { 1 - 2 } NT & $(34.77 ; 46.2)$ & $44.91(38.15 ; 55.2)$ \\
$59.1(53.05 ; 65.26)$ & $55.35(45.53 ; 68.06)$ \\
$41.15(36.6 ; 45.1)$ & $34.6(29.31 ; 41.85)$ \\
$24.38(23.15 ; 26.82)$ & $26.59(24.17 ; 29.69)$ \\
$0.85(0.8 ; 0.87)$ & $0.83(0.8 ; 0.86)$ \\
$8.74(8.35 ; 9.85)$ & $9.31(8.73 ; 10.39)$ \\
$47(39 ; 53.5)$ & $43.25(38 ; 58.5)$ \\
$1.38(1.27 ; 1.46)$ & $1.27(1.24 ; 1.39)$ \\
$0.73(0.68 ; 0.78)$ & $0.78(0.72 ; 0.81)$ \\
$0.93(0.92 ; 0.94)$ & $0.93(0.92 ; 0.94)$ \\
$2.36(2.33 ; 2.38)$ & $2.39(2.36 ; 2.43)$ \\
$5.27(4.76 ; 5.73)$ & $4.68(2.27 ; 5.17)$ \\
$0.6(0.58 ; 0.66)$ & $0.58(0.53 ; 0.63)$ \\
$130.9(124.4 ; 142.2)$ & $133.8(121.6 ; 152.2)$ \\
$4.52(4.11 ; 4.79)$ & $4.93(4.36 ; 5.21)$ \\
$0.13(0.12 ; 0.16)$ & $0.12(0.1 ; 0.14)$ \\
\hline
\end{tabular}




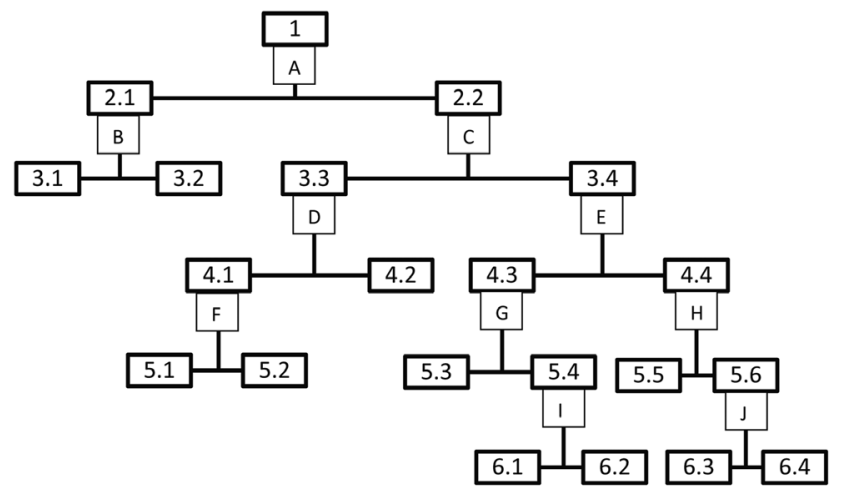

\begin{tabular}{|l|c|c|c|c|c|c|c|c|c|}
\hline \multirow{2}{*}{ Box } & \multirow{2}{*}{ CUT OFF } & \multicolumn{2}{|c|}{$F A$} & \multicolumn{2}{c|}{$F V C P$} & \multicolumn{2}{c|}{$F$} & \multicolumn{2}{c|}{ TOTAL } \\
\cline { 3 - 10 } & & $(\mathrm{N})$ & $(\%)$ & $(\mathrm{N})$ & $(\%)$ & $(\mathrm{N})$ & $(\%)$ & $(\mathrm{N})$ & $(\%)$ \\
\hline 1-Total & & 42 & 39.5 & 47 & 40.1 & 20 & 19.0 & 109 & 100.0 \\
\hline A-CV-AR & & & & & & & & & \\
\hline 2.1 & $\leq 14.99$ & 25 & 80.0 & 1 & 3.0 & 4 & 10.0 & 30 & 27.5 \\
\hline 2.2 & $>14.99$ & 17 & 21.5 & 46 & 59.2 & 16 & 20.0 & 79 & 72.5 \\
\hline B-CV-STDEV & & & & & & & & & \\
\hline 3.1 & $\leq 16.45$ & 1 & 25.0 & 0 & 0.0 & 3 & 75.0 & 4 & 3.7 \\
\hline 3.2 & $>16.45$ & 24 & 92.0 & 1 & 3.9 & 1 & 3.9 & 26 & 20.9 \\
\hline C-CV-Median & & & & & & & & & \\
\hline 3.3 & $\leq 27.47$ & 0 & 0.0 & 24 & 92.3 & 2 & 7.7 & 26 & 23.9 \\
\hline 3.4 & $>27.47$ & 17 & 32.1 & 22 & 41.5 & 14 & 26.4 & 53 & 49.6 \\
\hline D-STDEV & & & & & & & & & \\
\hline 4.1 & $\leq 60.96$ & 0 & 0.0 & 24 & 96.0 & 1 & 4.0 & 25 & 22.9 \\
\hline 4.2 & $>60.96$ & 0 & 0.0 & 0 & 0.0 & 1 & 100.0 & 1 & 0.9 \\
\hline E-CV-Fractal & & & & & & & & & \\
\hline 4.3 & $\leq 2.18$ & 10 & 39.2 & 7 & 20.6 & 14 & 41.2 & 34 & 31.2 \\
\hline 4.4 & $>2.18$ & 4 & 21.1 & 15 & 79.9 & 0 & 0.0 & 19 & 17.4 \\
\hline F-Perimeter & & & & & & & & & \\
\hline 5.1 & $\leq 42.00$ & 0 & 0.0 & 24 & 100.0 & 0 & 0.0 & 24 & 22.0 \\
\hline 5.2 & $>42.00$ & 0 & 0.0 & 0 & 0.0 & 1 & 100.0 & 1 & 0.9 \\
\hline G-Entropy & & & & & & & & & \\
\hline 5.3 & $\leq 4.69$ & 5 & 15.0 & 5 & 15.0 & 14 & 70.0 & 20 & 19.0 \\
\hline 5.4 & $>4.69$ & 10 & 71.4 & 4 & 29.6 & 0 & 0.0 & 14 & 12.9 \\
\hline H-AR & & & & & & & & & \\
\hline 5.5 & $>1.29$ & 0 & 75.0 & 1 & 25.0 & 0 & 0.0 & 4 & 0.7 \\
\hline 5.6 & & 1 & 6.7 & 14 & 90.3 & 0 & 0.0 & 15 & 13.9 \\
\hline I-Solidity & & & & & & & & & \\
\hline 6.1 & $\leq 0.94$ & 10 & 100.0 & 0 & 0.0 & 0 & 0.0 & 10 & 9.2 \\
\hline 6.2 & & 0 & 0.0 & 4 & 100.0 & 0 & 0.0 & 4 & 3.7 \\
\hline J-AR & & & & & & & & & \\
\hline 6.3 & $>1.69$ & 0 & 0.0 & 14 & 100.0 & 0 & 0.0 & 14 & 12.9 \\
\hline 6.4 & & 1 & 100.0 & 0 & 0.0 & 0 & 0.0 & 1 & 0.9 \\
\hline
\end{tabular}

\section{Figure 2}

Classification by the method Classification and Regression Trees (CRT), with algorithm of twoing, of the follicular adenomas (FA), follicular carcinomas (FC) and follicular variant of papillary carcinomas (FVPC), from the evaluated nuclear parameters. The numbers and letters of the flow chart are explained in the table. AR, Aspect Ratio; CV, coefficient of variation; DX, diagnosis; RA, roughness; PERIM, Perimeter; STDEV, standard deviation of gray intensity.

specificities (between 92.1\% and 100\%) and AUC (between 0.93 and 0.95) were obtained when the assessment method was used for classifying tumor type. Given the diagnostic uncertainty between FC and FA (2), we analyzed the validity of the classification method for these two tumors and correctly diagnosed 100\% of the samples. Similarly, when only FVPC and FA were assessed, $100 \%$ of the samples were classified correctly.

Other studies that used computerized nuclear image analysis to assess thyroid tumors reported correct global classification rates of $62-100 \%(1,5)$. The reasons for classification rate variability may involve the sample size, the number and type of the nuclear parameters evaluated and the interference of other factors, such as those related

Table 3 Validity of the use of computed nuclear morphometry analysis, with the Classification and Regression Trees (CRT) analysis, as a classificatory method.

\begin{tabular}{|c|c|c|c|}
\hline & \multicolumn{3}{|c|}{ Tumors } \\
\hline & FA & FVPC & FC \\
\hline Sensitivity (\%) & 90.5 & 89.4 & 95.0 \\
\hline Specificity (\%) & 95.5 & 100.0 & 92.1 \\
\hline PPV (\%) & 92.7 & 100.0 & 73.1 \\
\hline NPV $(\%)$ & 94.1 & 92.5 & 98.8 \\
\hline Area under the ROC curve & 0.93 & 0.95 & 0.94 \\
\hline
\end{tabular}

FA, follicular adenomas; FC, follicular carcinomas; FVPC, follicular variant of papillary carcinoma; NPV, negative predictive value; PPV, positive predictive value.

http://www.endocrineconnections.org https://doi.org/10.1530/EC-18-0237

(c) 2018 The authors Published by Bioscientifica Ltd to the tumors studied. Indeed, small sample sizes and assessment of few nuclear parameters may affect the results (1). The present study assessed 109 tumors, a reasonably robust number, and 33 nuclear parameters, including morphometric and texture features, and secondary nuclear indicators, which enabled more accurate analysis of each nucleus, and consequently, of each tumor. Apparently, the rate of correct tumor diagnosis increases with the number of studied parameters $(7,11)$.

Some nuclear parameters included in the present study have already been used by other authors and proved promising for the final characterization of the various follicular lesions $(4,5,8,19,22)$. Nonetheless, studies using secondary indicators (CV) were not found. In the present study, secondary indicators contributed to the high percentages of correct classification in the CRT regression model. Other problems that could affect the results are the inclusion of high tumor subtype diversity and disregarding the factor tumor size, that is, not correcting nuclear parameters by size $(1,7,11)$, which could limit the usefulness of the method to lesions of certain diameters $(11,13)$. The present study assessed only follicular-patterned tumors. Although FCs had greater diameters, tumor dimension was not associated with nuclear parameters, suggesting that tumor size does not influence nuclear variables. Thus, our results suggest that the method may be used in thyroid tumors regardless of their dimensions.

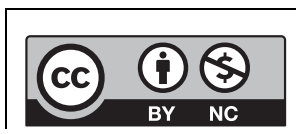

This work is licensed under a Creative Commons Attribution-NonCommercial 4.0 International License. 


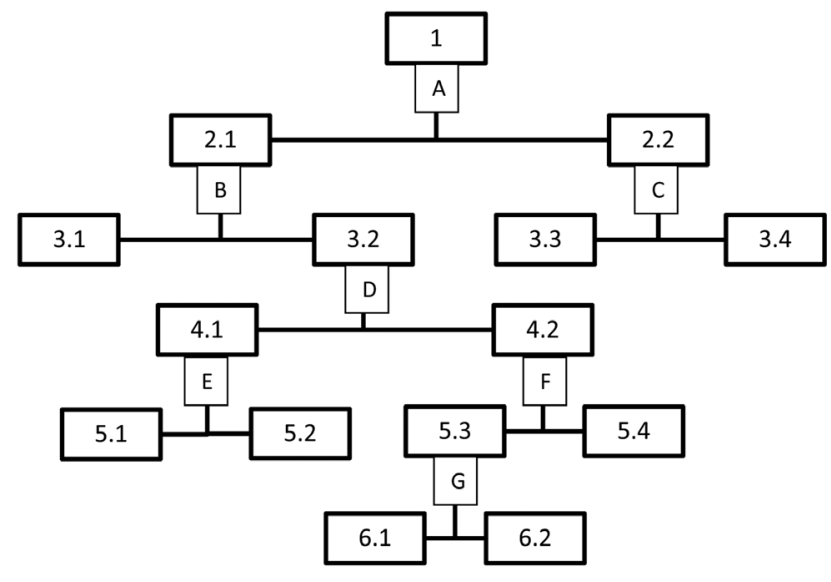

\begin{tabular}{|l|c|c|c|c|c|c|c|}
\hline \multirow{2}{*}{ Box } & \multirow{2}{*}{ CUT OFF } & \multicolumn{2}{c|}{$F A$} & \multicolumn{2}{c|}{$F C$} & \multicolumn{2}{c|}{ TOTAL } \\
\cline { 3 - 8 } & & $(\mathrm{N})$ & $(\%)$ & $(\mathrm{N})$ & $(\%)$ & $(\mathrm{N})$ & $(\%)$ \\
\hline 1-Total & & 42 & 67.7 & 20 & 32.3 & 62 & 100.0 \\
\hline A-Perimeter & & & & & & & \\
\hline 2.1 & $\leq 32.85$ & 40 & 80.0 & 10 & 20.0 & 50 & 80.6 \\
\hline 2.2 & $>32.85$ & 2 & 16.7 & 10 & 83.3 & 12 & 19.4 \\
\hline B-CV-AR & & & & & & & \\
\hline 3.1 & $\leq 12.14$ & 0 & 0.0 & 3 & 100.0 & 3 & 4.8 \\
\hline 3.2 & $>12.14$ & 40 & 85.1 & 7 & 14.9 & 47 & 75.8 \\
\hline C- Entropy & & & & & & & \\
\hline 3.3 & $\leq 5.52$ & 0 & 0.0 & 10 & 100.0 & 10.0 & 16.1 \\
\hline 3.4 & $>5.52$ & 2 & 100.0 & 0 & 0.0 & 2 & 3.2 \\
\hline D-CV-Entropy & & & & & & & \\
\hline 4.1 & $\leq 0.53$ & 34 & 97.1 & 1 & 2.9 & 35 & 56.5 \\
\hline 4.2 & $>0.53$ & 6 & 50.0 & 6 & 50.0 & 12 & 19.4 \\
\hline E-CV-Area & & & & & & & \\
\hline 5.1 & $\leq 14.00$ & 0 & 0.0 & 1 & 100.0 & 1 & 1.6 \\
\hline 5.2 & $>14.00$ & 34 & 100.0 & 0 & 0.0 & 34 & 54.8 \\
\hline F- Entropy & & & & & & & \\
\hline 5.3 & $\leq 4.68$ & 2 & 25.0 & 6 & 75.0 & 8 & 12.9 \\
\hline 5.4 & $>4.68$ & 4 & 100.0 & 0 & 0.0 & 4 & 6.5 \\
\hline G-CV-Circ & & & & & & & \\
\hline 6.1 & $\leq 15.00$ & 2 & 100.0 & 0 & 0.0 & 2 & 3.2 \\
\hline 6.2 & $>15.00$ & 0 & 0.0 & 6 & 100.0 & 6 & 9.7 \\
\hline
\end{tabular}

Figure 3

Classification by the method Classification and Regression Trees (CRT), with algorithm of twoing, of the follicular adenomas (FA) and follicular carcinomas (FC), from the evaluated nuclear parameters. The numbers and letters of the flow chart are explained in the table. AR, Aspect Ratio; CIRC, circularity; CV, coefficient of variation; DX, diagnosis; PERIM, perimeter.

This study has some limitations. A first limitation would be the applicability of the technique, which is somewhat time demanding as it requires nuclear image analysis. However, the time required for such task varies between individuals and decreases with experience, until it plateaus at about 30 min per case in our experience. This study's results could encourage the development of automated systems to optimize slide selection time and analysis. Another limitation would be the size of trees and number of knots resulting from CRT model analysis. Large trees may not be useful and may be associated with overfitting, thereby providing no explanatory power. However, the trees presented here could be considered only of moderate size. Moreover, as distinguishing tumors through pathological characteristics is difficult, it is expected that the variables originated from those characteristics might also be difficult to evaluate, which involves a greater number of knots. Another limitation regards the sample size, which could still be considered not large enough, although other studies have already obtained meaningful results with even smaller sample sizes (1). In addition, the number of nuclei assessed was based on a pilot study that determined the minimum sample size, and this parameter can be further optimized. It is important to emphasize that this is a preliminary study, in which the evaluation algorithm was developed. The next step will consist of selecting a much larger sample to validate the observed results.

$$
\begin{aligned}
& \text { http://www.endocrineconnections.org } \\
& \text { https://doi.org/10.1530/EC-18-0237 }
\end{aligned}
$$

Despite the limitations listed above, the high sensitivity and specificity of the method used by the present study makes it an important tool for aiding the histological diagnosis of follicular-patterned cases. In addition, these preliminary results stimulate the implementation of future studies with distinct designs, which could include more tumor subtypes, such as the recently proposed NIFTP (noninvasive follicular thyroid neoplasm with papillary-like nuclear features) (23, 24); the exploration of clinical, laboratorial, and prognostic variables (25); and the evaluation of nuclear morphometric and chromatin texture characteristics also of the follicular lesions from cytological samples.

In conclusion, computerized image analysis of nuclear features showed to be a promising diagnostic support tool for the histological differentiation between FA, FC and FVPC, with high sensitivity and specificity. Therefore, this inexpensive, reproducible and operatorindependent method might represent a valuable diagnostic support tool for the assessment of follicularpatterned tumors and particularly, for differentiating FA from FC. However, due to the considerations and limitations mentioned above, the preliminary results presented in this study should yet be validated, and then confirmed by independent groups. Moreover, other studies are needed to assess the applicability of these findings in cytological materials with indeterminate diagnosis. 


\section{Supplementary data}

This is linked to the online version of the paper at https://doi.org/10.1530/ EC-18-0237.

\section{Declaration of interest}

The authors declare that there is no conflict of interest that could be perceived as prejudicing the impartiality of the research reported.

\section{Funding}

This study received financial support from Fundação de Amparo à Pesquisa do Estado de São Paulo (FAPESP; process number 2014/10028-2), and PIBIC/PROPE-Unesp (process number 33347).

\section{Acknowledgments}

The authors thank to Fundação de Amparo à Pesquisa do Estado de São Paulo (FAPESP; process number 2014/10028-2), and PIBIC/PROPE-Unesp (process number 33347) for the research support and to Marcos Roberto Franchi and Luiz Fernando Franchi for the help in processing the histological material.

\section{References}

1 Wang W, Ozolek JA \& Rohde GK. Detection and classification of thyroid follicular lesions based on nuclear structure from histopathology images. Cytometry 201077 485-494. (https://doi. org/10.1002/cyto.a.20853)

2 Heffess CS \& Thompson LD. Minimally invasive follicular thyroid carcinoma. Endocrine Pathology 200112 417-422. (https://doi. org/10.1385/EP:12:4:417)

3 Mendaçolli PJ, Brianezi G, Schmitt JV, Marques ME \& Miot HA. Nuclear morphometry and chromatin textural characteristics of basal cell carcinoma. Anais Brasileiros de Dermatologia 201590 874-878. (https://doi.org/10.1590/abd1806-4841.20154076)

4 Frasoldati A, Flora M, Pesenti M, Caroggio A \& Valcavil R. Computerassisted cell morphometry and ploidy analysis in the assessment of thyroid follicular neoplasms. Thyroid 200111 941-946. (https://doi. org/10.1089/105072501753211000)

5 Gupta N, Sarkar C, Singh R \& Karak AK. Evaluation of diagnostic efficiency of computerized image analysis based quantitative nuclear parameters in papillary and follicular thyroid tumors using paraffinembedded tissue sections. Pathology and Oncology Research 20017 46-55. (https://doi.org/10.1007/BF03032605)

6 Murata SI, Mochizuki K, Nakazawa T, Kondo T, Nakamura N, Yamashita H, Urata Y, Ashihara T \& Katoh R. Morphological abstraction of thyroid tumor cell nuclei using morphometry with factor analysis. Microscopy Research and Technique 200361 457-462. (https://doi.org/10.1002/jemt.10355)

7 Demir C \& Yener B. Automated cancer diagnosis based on histopathological images: a systematic survey. In Technical Report cTR-05-09, Rensselaer Polytechnic Institute, Department of Computer Science. New York, NY, USA: Rensselaer Polytechnic Institute, 2005.

8 Karslioglu Y, Celasun B \& Gunhan O. Contribution of morphometry in the differential diagnosis of fine-needle thyroid aspirates. Cytometry 200565 22-28. (https://doi.org/10.1002/cyto.b.20024)
9 Proietti A, Sartori C, Borrelli N, Giannini R, Materazzi G, Leocata P, Elisei R, Vitti P, Miccoli P \& Basolo F. Follicular-derived neoplasms: morphometric and genetic differences. Journal of Endocrinological Investigation 201036 1055-1061. (https://doi.org/10.3275/9063)

10 Jung C \& Kim C. Impact of the accuracy of automatic segmentation of cell nuclei clusters on classification of thyroid follicular lesions. Cytometry 201485 709-718. (https://doi.org/10.1002/cyto.a.22467)

11 Murata SI, Mochizuki K, Nakazawa T, Kondo T, Nakamura N, Yamashita H, Urata Y, Ashihara T \& Katoh R. Detection of underlying characteristics of nuclear chromatin patterns ofthyroidtumor cells using texture and factor analyses. Cytometry 200249 91-95. (https:// doi.org/10.1002/cyto.10162)

12 Rodenacker K \& Bengtsson E. A feature set for cytometry on digitized microscopy images. Analytical Cellular Pathology 200325 1-36. (https://doi.org/10.1155/2003/548678)

13 Metze K, Ferreira RC \& Adam RL. Classification ofthyroidfollicular lesions based on nuclear texture features-lesion size matters. Cytometry 201077 1101-1102. (https://doi.org/10.1002/ cyto.a.20982)

14 Lloyd RV, Osamura RY, Kloppel G \& Rosai J. WHO Classification of Tumours of Endocrine Organs, 4th ed. Lyon, France: IARC Press, 2017.

16 Crissman JD, Drozdowicz S, Johnson C \& Kini SR. Fine needle aspiration diagnosis of hyperplastic and neoplastic follicular nodules of the thyroid - a morphometric study. Analytical and Quantitative Cytology and Histology 199113 321-328.

17 Loh W-Y. Classification and regression trees. WIREs Data Mining and Knowledge Discovery 20111 14-23. (https://doi.org/10.1002/widm.8)

18 Gil J \& Wu HS. Application of image analysis to anatomic pathology: realities and promises. Cancer Investigation 200321 950-959. (https:// doi.org/10.1081/CNV-120025097)

19 Kayser K, Hoshang SA, Metze K, Goldmann T, Vollmer E, Radziszowski D, Kosjerina Z, Mireskandari M \& Kayser G. Textureand object-related automated information analysis in histological still images of various organs. Analytical and Quantitative Cytology and Histology $200830323-335$.

20 Mulrane L, Rexhepaj E, Penney S, Callanan JJ \& Gallagher WM. Automated image analysis in histopathology: a valuable tool in medical diagnostics. Expert Review of Molecular Diagnostics $2008 \mathbf{8}$ 707-725. (https://doi.org/10.1586/14737159.8.6.707)

21 Nikonenko AG \& Bozhok YM. Simple cumputational technique to quantify nuclear shape asymmetry. Cytometry 201587 309-314. (https://doi.org/10.1002/cyto.a.22612)

22 Doudkine A, Macaulay C, Poulin N \& Palcic B. Nuclear texture measurements in image cytometry. Pathologica 199587 286-299.

23 Nikiforov YE, Seethala RR, Tallini G, Baloch ZW, Basolo F, Thompson LD, Barletta JA, Wenig BM, Al Ghuzlan A, Kakudo K, et al. Nomenclature revision for encapsulated follicular variant of papillary thyroid carcinoma: a paradigm shift to reduce overtreatment of indolent tumors. JAMA Oncology 20168 1023-1029. (https://doi. org/10.1001/jamaoncol.2016.0386)

24 Maletta F, Massa F, Torregrossa L, Duregon E, Casadei GP, Basolo F, Tallini G, Volante M, Nikiforov YE \& Papotti M. Cytological features of 'noninvasive follicular thyroid neoplasm with papillarylike nuclear features' and their correlation with tumor histology. Human Pathology 201654 134-142. (https://doi.org/10.1016/j. humpath.2016.03.014)

25 Shih SR, Chang YC, Li HY, Liau JY, Lee CY, Chen CM \& Chang TC. Preoperative prediction of papillary thyroid carcinoma prognosis with the assistance of computerized morphometry of cytology samples obtained by fine needle aspiration: preliminary report. Head and Neck 201335 28-34. (https://doi.org/10.1002/hed.22909)

Received in final form 20 June 2018

Accepted 3 July 2018

Accepted Preprint published online 4 July 2018 http://www.endocrineconnections.org https://doi.org/10.1530/EC-18-0237
C 2018 The authors Published by Bioscientifica Ltd
This work is licensed under a Creative Commons Attribution-NonCommercial 4.0 International License. 